\title{
CYP2D6 polymorphisms and their influence on risperidone treatment
}

Apichaya Puangpetch'

Natchaya Vanwong'

Nopphadol Nuntamool ${ }^{2}$

Yaowaluck Hongkaew'

Monpat Chamnanphon'

Chonlaphat Sukasem'

'Division of Pharmacogenomics and Personalized Medicine, Department of Pathology, Faculty of Medicine Ramathibodi Hospital, ${ }^{2}$ Molecular Medicine, Faculty of Science, Mahidol University, Bangkok, Thailand
Correspondence: Chonlaphat Sukasem Division of Pharmacogenetics and Personalized Medicine, Department of Pathology, Faculty of Medicine Ramathibodi Hospital, Mahidol University, Bangkok, Thailand

Tel +66 22004331

Fax +6622004332

Email chonlaphat.suk@mahidol.ac.th
This article was published in the following Dove Press journal:

Pharmacogenomics and Personalized Medicine

I December 2016

Number of times this article has been viewed
Abstract: Cytochrome P450 enzyme especially CYP2D6 plays a major role in biotransformation. The interindividual variations of treatment response and toxicity are influenced by the polymorphisms of this enzyme. This review emphasizes the effect of CYP2D6 polymorphisms in risperidone treatment in terms of basic knowledge, pharmacogenetics, effectiveness, adverse events, and clinical practice. Although the previous studies showed different results, the effective responses in risperidone treatment depend on the CYP2D6 polymorphisms. Several studies suggested that CYP2D6 polymorphisms were associated with plasma concentration of risperidone, 9-hydroxyrisperidone, and active moiety but did not impact on clinical outcomes. In addition, CYP2D6 poor metabolizer showed more serious adverse events such as weight gain and prolactin than other predicted phenotype groups. The knowledge of pharmacogenomics of CYP2D6 in risperidone treatment is increasing, and it can be used for the development of personalized medication in term of genetic-based dose recommendation. Moreover, the effects of many factors in risperidone treatment are still being investigated. Both the CYP2D6 genotyping and therapeutic drug monitoring are the important steps to complement the genetic-based risperidone treatment. Keywords: $C Y P 2 D 6$, risperidone, polymorphisms, adverse drug reaction, pharmacogenetics, pharmacokinetics, pharmacodynamics

\section{Introduction}

Risperidone is an atypical antipsychotic (AAP) drug that is being prescribed for the treatment of irritability or aggression in autism, schizophrenia, and acute bipolar mania. Risperidone exerts its pharmacologic effects by binding to and inhibiting high-affinity serotonin and dopamine receptor. ${ }^{1}$ As a result, treating these symptoms can reduce the disease severity and thus can improve quality of life of patients. Risperidone is metabolized by hepatic metabolism via the CYP2D6 enzymatic pathway to its major active metabolite, 9-hydroxyrisperidone or paliperidone, which has pharmacologic effects equivalent to those of risperidone. Therefore, therapeutic response on risperidone administration is the total of the active moiety of plasma risperidone and 9-hydroxyrisperidone concentrations. There are evidences of various differences in risperidone treatment in different individuals, which may explain the pharmacologic activity between risperidone and 9-hydroxyrisperidone that further explains the difference in clinical outcomes of CYP2D6 genetic polymorphisms. To date, $>100$ allele variants of CYP2D6 genotype have been proposed and predicted in 4 different phenotypes: extensive (normal activity), intermediate (reduced activity), poor (no activity), and ultra-rapid (high activity) metabolism. 
Because the long-term use of these psychotropic medications may cause some adverse effects, ${ }^{2}$ various concerns arise regarding the health implications of its side effects as well as its medication compliance, which lead to symptom relapse which is a common challenge in clinical management of psychiatric disorder. ${ }^{3}$ Pharmacogenetic testing can thus help predict the response or probability of adverse effects and optimize the clinical decisions. Therefore, the objective of this review was to summarize and evaluate the pharmacogenetic effects of CYP2D6 polymorphism on risperidone therapy, both efficacy and adverse drug reaction (ADR), including insights for the potential impact of this field on the safe and effective use of medications with future prospects and challenges.

\section{Pharmacokinetic and pharmacodynamic profile of risperidone Pharmacokinetics}

Risperidone has the property of being well absorbed. The absolute oral bioavailability of risperidone is $\sim 70 \%$. The relative oral bioavailability of risperidone from a tablet is 94\% when compared to that from a solution. Risperidone is rapidly distributed, and the volume of distribution is $1-2$ $\mathrm{L} / \mathrm{kg}$. The major active metabolite is 9-hydroxyrisperidone (paliperidone); both are the substrates of the drug transporter P-glycoprotein (P-gp). Thus, P-gp affects both the absorption and brain concentrations of this drug. A study in mouse model showed the effect of P-gp in total brain-to-plasma $(\mathrm{B} / \mathrm{P})$ ratios of risperidone and its active metabolite. The brain concentrations and $\mathrm{B} / \mathrm{P}$ ratios of risperidone (13.1fold and 12-fold) and 9-hydroxyrisperidone (29.4-fold and 29-fold) were significantly higher in the $A B C B 1$ knockout mice than wild-type mice. ${ }^{4}$ The other mouse models show similar results. The $\mathrm{B} / \mathrm{P}$ ratios of risperidone and its active metabolite 9-hydroxyrisperidone (10-fold and 17-fold) were significantly higher in knockout mice than wild-type mice and also correlate with cerebrospinal fluid/plasma ratios (6.3-fold and 9.3-fold). ${ }^{5}$ These results indicate that P-gp in the blood-brain barrier significantly influences the brain concentrations of risperidone and 9-hydroxyrisperidone.

Risperidone is greatly metabolized in the liver by cytochrome P450 2D6 enzymes (CYP2D6). An active metabolite by main hydroxylation pathway is 9-hydroxyrisperidone. Another minor metabolic pathway is through $\mathrm{N}$-dealkylation. An in vitro study of several human cytochrome P450 (CYP) enzymes showed the activity on the metabolism of risperidone such as CYP1A1, CYP1A2, CYP2C8, CYP2C9-arg144,
CYP2C9-cys144, CYP2C19, CYP2D6, CYP3A4, and CYP3A5 enzymes. Three CYP enzymes, CYP2D6, CYP3A4, and CYP3A5, showed the main activity of metabolizing risperidone to 9-hydroxyrisperidone, with activities of 7.5, 0.4, and $0.2 \mathrm{pmol} \mathrm{pmol}^{-1} \mathrm{CYP} \mathrm{min}^{-1}$, respectively. Moreover, a study on human liver microsomes showed high correlation in the activities of CYP2D6 and CYP3A in the formation of 9-hydroxyrisperidone. This result is confirmed by using inhibitors of CYP2D6 (quinidine) and CYP3A4 (ketoconazole) to inhibit the formation of 9-hydroxyrisperidone. Thus, both CYP2D6 and CYP3A4 are the main enzymes for the metabolism of risperidone to 9-hydroxyrisperidone. ${ }^{6}$

\section{Pharmacodynamics}

Risperidone is the dopamine, $\mathrm{D}_{1}\left(\mathrm{D}_{1}, \mathrm{D}_{5}\right)$ and $\mathrm{D}_{2}$ family $\left(\mathrm{D}_{2}\right.$, $\mathrm{D}_{3}$, and $\mathrm{D}_{4}$ ), receptor antagonist. Moreover, it also has a high-affinity antagonist effect for the serotonin type $2\left(5 \mathrm{HT}_{2}\right)$, $\alpha_{1}$ and $\alpha_{2}$ adrenergic, and $H_{1}$ histaminergic receptors. ${ }^{7}$ The antagonist effects were found in both in vitro and in vivo studies. ${ }^{89}$ Furthermore, new mechanism as partial uncompetitive inhibition on D-amino acid oxidase (DAO) was investigated. The results showed a protective effect of risperidone from D-amino acid-induced cell death. The new antischizophrenia mechanism of risperidone has been proposed..$^{10}$ Risperidone blocks the mesolimbic pathway, the prefrontal cortex limbic pathway, and the tuberoinfundibular pathway in the central nervous system. These pathways can increase the secretion of prolactin causing sexual side effects, such as galactorrhea, infertility, and gynecomastia.

Risperidone has high affinity for the serotonin type 2 (5HT2A, Ki of $0.6 \pm 0.2 \mathrm{nM}$ and $5 \mathrm{HT} 2 \mathrm{C}$ Ki of $26 \pm 5 \mathrm{nM}$ ) and dopamine type $2(\mathrm{D} 2, \mathrm{Ki}=3 \pm 1 \mathrm{nM}$ ) and type 4 (D4, Ki $=7 \pm 1 \mathrm{nM})$. Whereas, low to moderate affinity for serotonin type 1 (5HT1A, 5HT1C, and 5HT1D, Ki of 100-1325 nM) and dopamine type $1(\mathrm{Ki}=75 \mathrm{nM})$ and no affinity for cholinergic muscarinic receptors have been observed (inhibition of binding $<50 \%$ at concentrations $10,000 \mathrm{nM}) .{ }^{11}$

Other binding affinity studies also showed the similar result. ${ }^{12}$ Risperidone and its metabolite showed the potent binding at 5HT2A $(\mathrm{Kd}=0.15 \pm 0.02 \mathrm{nM}$ and $1.21 \pm 0.06$ $\mathrm{nM}), 5 \mathrm{HT} 2 \mathrm{C}(\mathrm{Kd}=32 \pm 4 \mathrm{nM}$ and $48 \pm 5 \mathrm{nM}), \mathrm{D} 2(\mathrm{Kd}=$ $3.77 \pm 0.04 \mathrm{nM}$ and $2.8 \pm 0.3 \mathrm{nM}), \alpha 1(\mathrm{Kd}=2.7 \pm 0.3 \mathrm{nM}$ and $10.1 \pm 0.8 \mathrm{nM}), \alpha 2(\mathrm{Kd}=8 \pm 1 \mathrm{nM}$ and $80 \pm 10 \mathrm{nM})$, and $\mathrm{H} 1$ histaminergic receptors $(\mathrm{Kd}=5.2 \pm 0.5 \mathrm{nM}$ and $3.4 \pm 0.4 \mathrm{nM}$ ), respectively. However, low-affinity binding of risperidone and 9-hydroxyrisperidone was found not only with $5 \mathrm{HT} 1 \mathrm{~A}(\mathrm{Kd}=190 \pm 20 \mathrm{nM}$ and $480 \pm 40 \mathrm{nM})$ but also with muscarinic receptor $(\mathrm{Kd}$ of $34,000 \pm 3000 \mathrm{nM}$ and 
$8800 \pm 500 \mathrm{nM}) .^{12}$ The pathway of pharmacokinetics and pharmacodynamics of risperidone was shown in Figure 1.

\section{Interethnic variation of CYP2D6 alleles across world populations}

CYP2D6 is the major enzyme in metabolism of many prescribed drugs (Table 1). The CYP2D6 gene is located on chromosome 22 (22q13.1) and is composed of 9 exons with an open reading frame of 1491 base pairs coding for 497 amino acids and 8 introns. ${ }^{13-16}$

Data on allelic distribution worldwide, modified from Hick et $\mathrm{al}^{17}{ }^{17}$ (Table 2) showed that the frequencies of CYP2D6 allele with nonfunctional enzyme activity, that is, CYP2D $6 * 3$, $* 4$, and *5 (gene deletion), are higher in Caucasian, American, African, and Middle East population and also found high allelic frequency in South/Central Asian. CYP2D6*4 (1846G $>A$, rs3892097) is the most frequent variant allele in European/Caucasian or European/North American population in $18.0 \%$ (minimum-maximum: $8.1 \%-33.4 \%$ ) and present in $70 \%-90 \%$ of all nonfunctional phenotypes. ${ }^{15,18}$ Moreover, $C Y P 2 D 6 * 36$ which is gene conversion (GC) or hybrid between CYP2D7 pseudogene and CYP2D6 (CYP2D6-2D7) in exon 9 results in nonfunctional CYP2D6 enzyme activity. ${ }^{19}$ CYP2D6*36 has rare frequency in almost of all the populations except Asian population; the highest allelic frequency of $* 36+* 10$ in Japanese which investigated and reported by Hosono et $\mathrm{a}^{20}$ and Kiyotani et $\mathrm{a}^{21}$ was $\sim 24.2 \%$ and $32.7 \%$, respectively. $C Y P 2 D 6^{*} 17$ has the most frequent, reduced enzyme activity in African (20\%, 9\%-34\%), and CYP2D6*41 $(2988 \mathrm{G}>\mathrm{A}, \mathrm{rs} 28371725)$ allele with decreased enzyme activity showed the highest allele frequency in Middle East (20\%, 15.2\%-29\%) and African (10.9\%, 1.4\%-25.3\%). However, allele with decreased enzyme activity, especially CYP2D6*10 (100C $>\mathrm{T}$, rs1065852), has highest frequencies in Asian population, especially Thai $(\sim 50 \%)^{22-26}$ and East Asian $(\sim 42.7 \%)^{17}$ populations, but it is rare in Caucasian. ${ }^{27-29}$ In a previous study by our group, it was found that the data of allele distribution resemble that in East Asian populations but differ from other populations. Many tools were used for the detection of CYP2D6 genotyping, that is, microarray, allele specific primer extension (ASPE) (bead array), and TaqMan single-nucleotide polymorphism (SNP) genotyping along with TaqMan CNV kit. Perhaps, the different allele distribution of CYP2D6 gene may depend on several techniques that

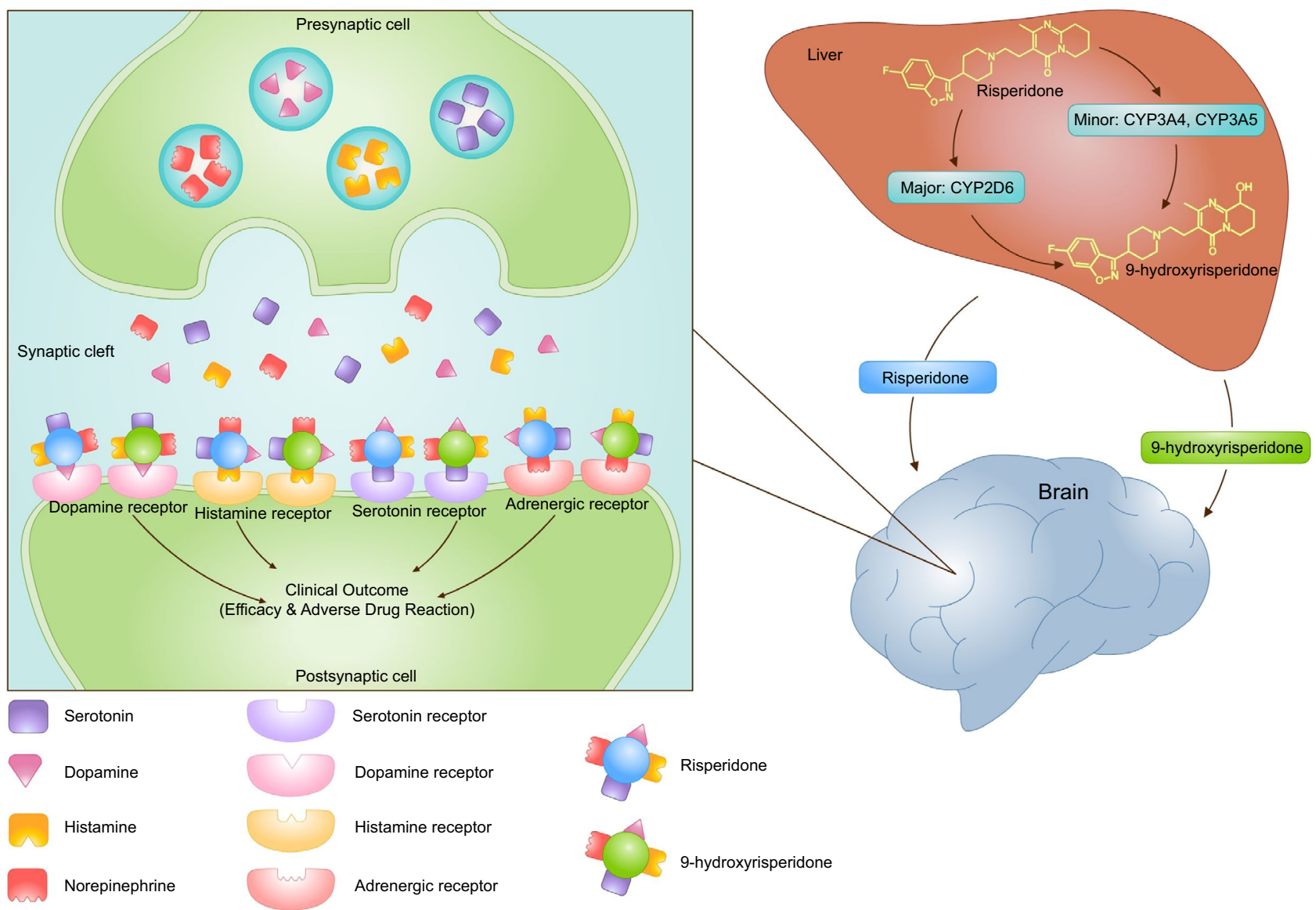

Figure I The pathway for pharmacokinetics and pharmacodynamics of risperidone. 
Table I Clinically relevant drug substrates for metabolism by CYP2D6 enzymes

\begin{tabular}{|c|c|c|c|c|c|}
\hline \multicolumn{6}{|c|}{ CYP2D6 substrates } \\
\hline Antidepressants & Beta blockers & Anti-cancer & Antipsychotics & & \\
\hline Amitriptyline & Alprenolol & Tamoxifen & Haloperidol & Mexiletine & Methoxyamphetamine \\
\hline Clomipramine & Carvedilol & & Perphenazine & Minaprine & Bufuralol \\
\hline Desipramine & Propafenone & & Risperidone & Nebivolol & Chlorpheniramine \\
\hline Imipramine & Bupranolol & & Thioridazine & Nortriptyline & Chlorpromazine \\
\hline Fluoxetine & Clonidine & & Zuclopenthixol & Ondansetron & Clonidine \\
\hline Paroxetine & Debrisoquine & & Atomoxetine & Oxycodone & Codeine \\
\hline Tamoxetine & Metoprolol & & Alprenolol & Perhexiline & Debrisoquine \\
\hline Trimipramine & Propranolol & & Amphetamine & Phenacetin & Dexfenfluramine \\
\hline Venlafaxine & Timolol & & Aripiprazole & Phenformin & Dextromethorphan \\
\hline
\end{tabular}

are used for detection in each laboratory besides the diverse ethnic groups. Interestingly, there are many rare alleles that have not yet been determined or could not be performed by the current assay such as $* 18, * 21, * 27, * 28, * 33, * 39$, $* 43-* 55, * 60, * 63, * 65, * 69, * 75$, and so on. Thus, the data of other rare or novel alleles which can be found in many populations around the world including Thai population might be missed. In addition, the samples in each study had many different genetic background or diseases, some were healthy volunteers whereas others suffered from many diseases such as breast cancer, sickle cell anemia, psychiatric, fatal intoxication cases, and so on, which affected the distribution of the allele frequency.

\section{"Predicted" phenotypes and "measured" metabolic phenotypes on medication}

Identification of allele depends on the changes in nucleotides or mutations which affect the changes in amino acid, which subsequently affect the changing protein structures and the characterization of enzyme activity including increased, decreased, and no enzyme activity that need to be determined in both in vitro and in vivo studies in order to confirm the exact enzyme activity. There are many functional CYP polymorphism patterns that result from the SNPs, that is, synonymous and nonsynonymous SNPs, nucleotide substitution, frameshift, splicing defect, CYP2D7/2D6 hybrid or GC, small insertion/deletion, tandem rearrangement, especially gene deletion, duplication, and multiplication. These variations of CYP2D6 gene could change protein function. Not only variants in the regions of exon protein coding are found, which is most important to amino acid changes, but also the data of mutations in all the regions of the gene including intronic, intergenic, promoter, and untranslated region (UTR) $)^{30,31}$ as well as CYP2D7/2D6 hybrid gene in both exon and intron regions are revealed..$^{32}$ The significant alteration of polymorphisms in CYP2D6 gene produces various forms of enzyme activity and biotransformation pathway of the currently prescribed drugs in clinical treatment. ${ }^{33}$ The variations of CYP2D6 genotype-phenotype were defined as active, inactive, reduced, and increased functional enzyme activity.

Examples of genotype-phenotype relationship on drug metabolism were summarized in Table 3. Many prescription drugs in the current clinical treatment are related to the biotransformation pathway of CYP2D6 enzyme. Anticancer drug, tamoxifen (selective estrogen receptor modulator), is a pivotal adjuvant drug in breast cancer therapy. As known to the scientists for a long time, tamoxifen was metabolized by CYP2D6 to endoxifen, N-desmethyl-tamoxifen, and so on, which has more potent binding affinity with estrogen receptor. ${ }^{34}$ Hertz et al ${ }^{35}$ revealed that tamoxifen, a prodrug in the adjuvant treatment of breast cancer patients, was metabolized by CYP2D6 enzyme to its metabolite (endoxifen) and that the patients who carried IM (EM/IM, EM/PM, IM/IM, IM/PM) or PM (PM/PM) phenotype had reduced median endoxifen concentration compared with EM (EM/EM) phenotype.

Most of the antidepressant drugs were metabolized via CYP2D6 enzyme. Several previous studies used antidepressant drugs as model of transformable genotype to potential phenotype and showed the significantly different area under the concentration time curve (AUC) of nortriptyline drug among the patients who carried PM; IM phenotype had higher AUC than patients who carried EM phenotype (Table 3). ${ }^{36-37}$ Thus, the challenges of predicted phenotype used in clinical treatment depend on individual drug substrates and ethnic population samples.

In the case of risperidone treatment in autistic spectrum disorder, Novalbos et $\mathrm{a}^{38}$ reported that the metabolic ratio (MR) of the AUC for risperidone and 9-hydroxyrisperidone of patients with PM and IM had significantly different MR from EM. Furthermore, most of the pharmacokinetic parameters (AUC, $C_{\max }, T_{\max }, t_{1 / 2}$, and $\mathrm{Cl} / \mathrm{F}$ ) of risperidone 


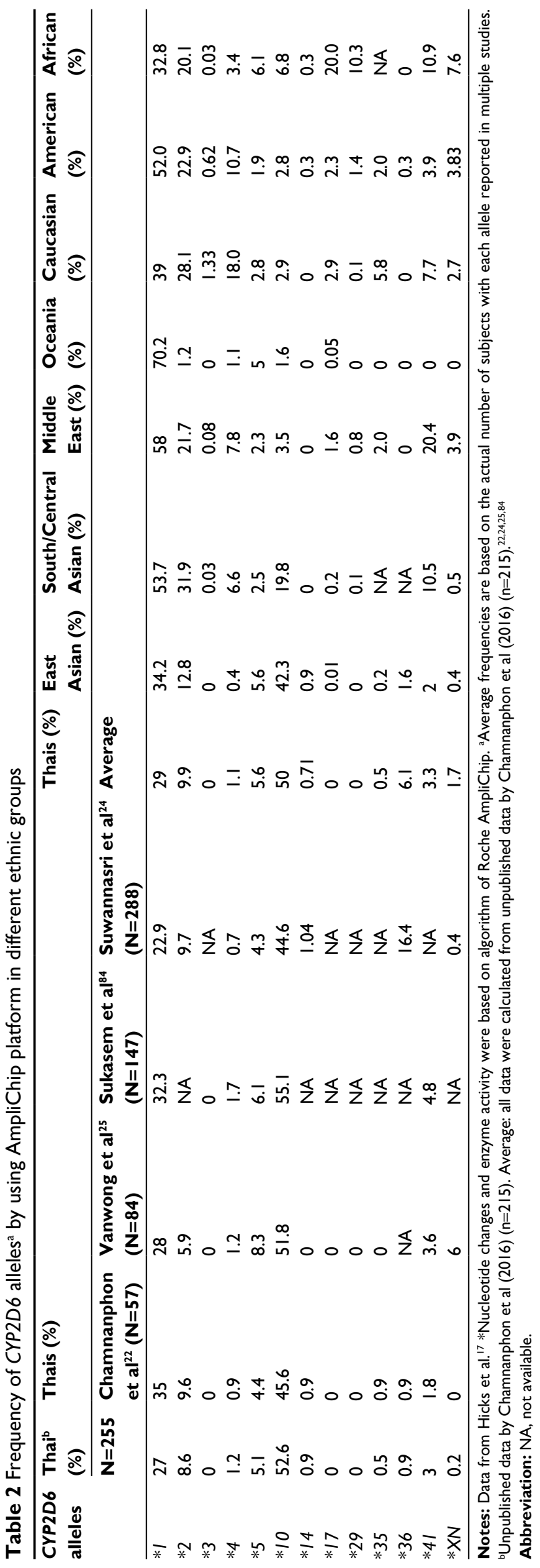

and 9-hydroxyrisperidone were significantly different in PM patients from the others (IM, EM, and UM) (Table 3).

The duplicated, multi-duplicated, or amplified CYP2D6 genes are copy number variations (CNVs). This result exhibits increased CYP2D6 enzyme activity and leads to higher plasma drug concentration in prodrug or lower plasma drug concentration in active drugs. Furthermore, functional alterations of CYP2D6 variants have been widely studied in the Japanese population, but the results remain inconsistent. . $^{16,21,39,40}$ Cassandra Willyard et a $\mathrm{l}^{41}$ suggested that the effect of CNV in a polymorphism was studied extensively because of its close association with drug metabolism, but many scientists still overlooked the importance and influence of gene duplication, deletion, and multiplication on drug response, although CNV has been used to understand the full spectrum of human genetic variation and also to assess the significance of such variation in disease association studies. Several well-known CNV genes such as CYP2A6, CYP2D6, GSTM1, GSTT1, SULT1A1, SULT1A3, UGT2B17, UGT2B7, UGT2B10, and $U G T 2 B 11$ are involved in drug metabolisms. ${ }^{33}$ However, some publications introduced the prevalence of CYP2D6 $\mathrm{CNV}$, exclusively there was less study about the significance of $\mathrm{CNV}$ in pharmacogenomic area. Beoris et $\mathrm{a}^{42}$ found that $12.6 \%(n=3,974 / 31,563)$ of all patients who were tested had zero $(0.14 \%, 43)$, one $(7.25 \%, 2,288)$, three or more copies of the CYP2D6 gene ( $\geq 3$ copy, $5.21 \%, 1,643$ ) in the American population. Sheng et $\mathrm{al}^{43}$ reported that low allele frequencies of $C Y P 2 D 6 * 5$ and $C Y P 2 D 6 * \times N$ were $4.82 \%(\mathrm{n}=35 / 363)$ and $0.69 \%(\mathrm{n}=5 / 363)$ in the Eastern Han Chinese population, respectively, and they focused on the details of duplication and multiplication including $C Y P 2 D 6^{*} 10 \times N(2,0.28 \%)$ and CYP $2 D 6^{*} 1 \times N(3,0.41 \%)$ and also found gene rearrangement in $\sim 11 \%$ of all the subjects. The investigations of CNV in drug biotransformation and functional enzyme activity are unclear. However, several scientists believed that $\mathrm{CNV}$ is an important part of drug metabolizing enzyme; in the future, potential research studies should determine the CYP2D6 variations in order to use the accurate predicted phenotype in clinical therapy.

\section{Interpretation of predicted phenotype of CYP2D6 and gene activity score}

Genetic variation of CYP2D6 gene is associated with CYP2D6 enzyme activity including decreased, increased, and nonfunctional enzyme activities. The CYP2D6 potential phenotypes include four phenotypes: poor metabolizers (PMs) lead to lack of functional enzyme activity because of 
Table 3 Relationship of CYP2D6 genotype-phenotype on drug metabolism categorized in different drug substrates

\begin{tabular}{|c|c|c|c|c|c|c|c|c|c|}
\hline \multirow{3}{*}{$\begin{array}{l}\text { Potential } \\
\text { phenotype }\end{array}$} & \multirow{2}{*}{$\begin{array}{l}\text { Example of } \\
\text { genotype }\end{array}$} & \multicolumn{2}{|l|}{ Tamoxifen } & \multirow{2}{*}{$\begin{array}{l}\text { Potential } \\
\text { phenotype }\end{array}$} & \multicolumn{3}{|c|}{ Antidepressant drug } & \multirow{2}{*}{\multicolumn{2}{|c|}{$\begin{array}{l}\text { Antipsychotic drug } \\
\text { Risperidone and } \\
\text { 9-hydroxyrisperidone }\end{array}$}} \\
\hline & & $\begin{array}{l}\text { Baseline } \\
\text { endoxifen } \\
(\mathrm{ng} / \mathrm{mL})\end{array}$ & $\begin{array}{l}\text { 4-Month } \\
\text { endoxifen } \\
(\mathrm{ng} / \mathrm{mL})\end{array}$ & & Nortriptylir & & & & \\
\hline & & Median & Median & & AUC & AUC & AUC & Phenotype & $M R($ mean $\pm S D)$ \\
\hline UM & NA & NA & NA & UM & 0.8 & & & UM & $0.08 \pm 0.03$ \\
\hline EM & EM/EM & 8.9 & 8.2 & EM & 1.3 & 1.8 & 1.7 & EM & $0.18 \pm 0.29$ \\
\hline \multirow[t]{4}{*}{ IM } & $\mathrm{EM} / \mathrm{IM}$ & 7.9 & 13.1 & IM & 3.6 & 3.1 & 3.0 & IM & $0.41 \pm 0.49$ \\
\hline & EM/PM & 6.1 & 8.9 & & & & & & \\
\hline & $\mathrm{IM} / \mathrm{IM}$ & 4.3 & 6.5 & & & & & & \\
\hline & IM/PM & 4.0 & 5.8 & & & & & & \\
\hline PM & $\mathrm{PM} / \mathrm{PM}$ & 2.4 & 6.1 & PM & 4.3 & 4.2 & 4.2 & PM & $3.4 I \pm 0.67$ \\
\hline Research groups & & Hertz et $\mathrm{al}^{3}$ & & & Dalen et $\mathrm{al}^{36}$ & Mellstrom et $\mathrm{al}^{37}$ & Bertilsson et $\mathrm{al}^{38}$ & Novalbos & et $\mathrm{al}^{39}$ \\
\hline
\end{tabular}

Abbreviations: AUC, area under the concentration time curve in $\mu \mathrm{M}$; EM, extensive metabolizer; IM, intermediate metabolizer; MR, metabolic ratio of the AUC for risperidone and 9-hydroxyrisperidone; NA, not available; PM, poor metabolizer; UM, ultra-rapid metabolizer; SD, standard deviation.

Table 4 Comparison of Allele and Gene Activity Score between 3 algorithms

\begin{tabular}{|c|c|c|c|c|c|c|c|c|}
\hline \multirow[t]{2}{*}{ AS } & \multirow[t]{2}{*}{ Gaedigk et al ${ }^{44}$} & \multirow{2}{*}{$\begin{array}{l}\text { Crews et al }{ }^{19} \text { and } \\
\text { Hicks et } \mathrm{al}^{17} \text { (CPIC) }\end{array}$} & \multirow[t]{2}{*}{ Allele } & \multirow[t]{2}{*}{ Hertz et $\mathbf{a l}^{35}$} & \multirow{2}{*}{$\begin{array}{l}\text { Diplotypes } \\
\text { Microarray and } \\
\text { Bead array (ASPE) } \\
\text { rule-based }\end{array}$} & \multirow{2}{*}{$\begin{array}{l}\text { Diplotypes } \\
\text { Hertz et } \text { al }^{35}\end{array}$} & \multicolumn{2}{|c|}{ Gene Activity Score } \\
\hline & & & & & & & $\begin{array}{l}\text { Gaedigk } \\
\text { et } \mathrm{al}^{44}\end{array}$ & $\begin{array}{l}\text { Crews et al }{ }^{19} \\
\text { and Hicks et al }{ }^{17} \\
\text { (CPIC) }\end{array}$ \\
\hline 0 & $\begin{array}{l}* 3, * 4, * 4 \times N, * 5 \\
* 6, * 7, * 16, * 36 \\
* 40, * 42, * 56 B\end{array}$ & $\begin{array}{l}* 3, * 3 x N, * 4, * 4 x N, * 5, \\
* 6, * 6 x N, * 7, * 8, * 11, \\
* 12, * 13, * 14 A, * 15, \\
* 18, * 19, * 20, * 21, * 31, \\
* 36, * 36 x N, * 38, * 40, \\
* 42, * 44, * 47, * 51, * 56, \\
* 57, * 62, * 68, * 69, * 92, \\
* 100, * 101\end{array}$ & PM & $\begin{array}{l}* 3, * 4, * 5, * 6 \\
* 7, * 8, * 11, * 15 \\
* 19, * 20, * 40 \\
* 4 \times N\end{array}$ & 2 nonfunctional alleles & $\mathrm{PM} / \mathrm{PM}$ & 0 & 0 \\
\hline 0.5 & $\begin{array}{l}* 9, * 10, * 17, * 29 \\
* 41, * 45, * 46\end{array}$ & $\begin{array}{l}* 9, * 10, * 14 B, * 17, * 29 \\
* 41, * 49, * 50, * 54, * 55 \\
* 59, * 72\end{array}$ & IM & $\begin{array}{l}* 9, * 10, * 17 \\
* 29, * 36, * 4 I, \\
* I 7 x N, * 4 I x N\end{array}$ & $\begin{array}{l}\text { I nonfunctional allele } \\
\text { and I reduced activity } \\
\text { or } 2 \text { reduced activity } \\
\text { alleles }\end{array}$ & $\begin{array}{l}\text { EM/IM, EM/PM, } \\
\text { IM/IM, IM/PM }\end{array}$ & $0.5-1$ & 0.5 \\
\hline I & $\begin{array}{l}* 1, * 2, * 35, * 43 \\
* 45 \times N\end{array}$ & $\begin{array}{l}* 1, * 2, * 27, * 33, * 34, \\
* 35, * 39, * 45, * 46, \\
* 48, * 53\end{array}$ & EM & $* 1, * 2$, and $* 35$ & $\begin{array}{l}\text { At least I functional } \\
\text { allele }\end{array}$ & $\begin{array}{l}\text { EM/EM, UM/ } \\
\text { IM,UM/PM }\end{array}$ & I.5-2 & $\mathrm{I}-2$ \\
\hline$>1$ & $\begin{array}{l}* I \times N, * 2 \times N \\
* 35 \times N\end{array}$ & $\begin{array}{l}* 1 \times N, * 2 x N, * 35 x N, \\
* 45 x N\end{array}$ & UM & $\begin{array}{l}* I x N, * 2 x N \\
* 35 \times N\end{array}$ & $\begin{array}{l}\text { At least } 3 \text { copies of } \\
\text { functional allele }\end{array}$ & UM/UM,UM/EM & $>2$ & $>2$ \\
\hline
\end{tabular}

Abbreviations: AS, activity score; CPIC, Clinical Pharmacogenetics Implementation Consortium; EM, extensive metabolizer; IM, intermediate metabolizer; PM, poor metabolizer; UM, ultra-rapid metabolizer.

gene deletion or change of amino acid. Defective gene caused altered drug metabolism or would be eliminated in pharmacokinetic phase II (sulfation or glucuronidation); intermediate metabolizers (IMs) carry two reduced functional alleles or one reduced functional allele and nonfunctional allele; extensive metabolizers (EMs) carry two functional alleles or one functional allele, and this results in normal enzyme activity and drug concentration; and ultra-rapid metabolizers (UMs) carry more than two gene copies, duplicated, multiduplicated, or amplified CYP2D6 genes. This result in enzyme activity exhibits increased CYP2D6 enzyme activity and leads to higher plasma drug concentration in prodrug or lower plasma drug concentration in active drugs. ${ }^{33}$ The categorization of predicted phenotype or metabolizer status depends on drug probe substrates, which are challenging in each study, and it is important and difficult to translate CYP2D6 genotyping into potential phenotype. ${ }^{44}$ Presently, there are many different algorithms that have been used for the interpretation of predicted phenotype, and the system has not been standardized yet because of the complexity of translational genotype and accurately potential phenotype. Thus, many groups of researchers attempt to study and create new rule-based system called "Allele and Gene Activity Score" to give more detail precision and accuracy of phenotype. 


\section{Translation of genotype into predicted phenotypes through Allele and Gene Activity Scores}

Gaedigk et al ${ }^{44}$ Hertz et al, ${ }^{35}$ Crew et al,${ }^{19}$ and Hicks et al ${ }^{17}$ proposed classification of predicted phenotypes according to allele activity score (AS) of each algorithms according to microarray and bead array (ASPE) rule-based system. Based on these algorithms (Table 4), first, UM had at least 2 functional alleles, EM had at least 1 functional allele, IM had 1 nonfunctional allele, and 1 reduced activity or 2 reduced activity alleles, and $\mathrm{PM}$ had 2 nonfunctional alleles. Based on gene AS according to these studies, CYP2D6 alleles with increased enzyme activity (i.e., * $1 X N, * 2 X N, * 35 X N$, $* 45 X N$ ) were assigned to have AS as $>1$, alleles with normal enzyme activity (i.e., $* 1, * 2, * 35$ ) have AS as 1 , alleles with reduced enzyme activity (i.e., $* 10, * 14 B^{*}, * 41$ ) have AS as 0.5 , and alleles with nonfunctional enzyme activity (i.e., $* 4, * 5, * 36$ ) have AS as $0 . * 14 B$ was designated to unknown enzyme activity according to AmpliChip CYP450 rulebased, whereas reduced functional allele following CYP2D6 allele nomenclature * 36 was designated to nonfunctional enzyme activity according to Crews et al. ${ }^{19}$ The gene activity score was the sum of the values assigned to allele 1 and $2 .{ }^{107}$

The assignment of predicted or potential phenotypes is based upon CYP2D6 diplotypes. The score of CYP2D6 diplotype is defined as gene score that combines allele score 1 and allele score 2 according to Gaedigk et al ${ }^{44}$ and Borges et $\mathrm{a}^{45}$ including UM (>2), EM (1.5-2), IM (0.5-1), and PM (0). In addition, several rule-based systems of allele AS had different or ambiguous alleles among many studied such as $* 45 x N$ was assigned to have the score as 1 (normal function) by Gaedigk et al, ${ }^{44}$ whereas the score in Clinical Pharmacogenetics Implementation Consortium (Crews et a ${ }^{19}$ and Hicks et $\mathrm{al}^{17}$ ) was assinged as $>1$ (increased function). CYP2D6*36 and $* 36 x N$ were assigned score as 0 (nonfunctional) by Crews et al ${ }^{19}$ and Hicks et a ${ }^{17}$ in contrast to the study by Hertz et al, ${ }^{35}$ which reported that the score of this allele as 0.5 (decreased function), and furthermore, $* 17 x N$ and $* 41 x N$ were assigned a score of 0.5 . However, these models of allele and gene AS have to be validated and proved in larger group of population samples.

\section{Effect of CYP2D6 polymorphisms on the risperidone pharmacokinetics}

Risperidone is a widely used AAP agent and has potent antagonistic properties for both dopamine D2 and serotonin5HT2 receptors. ${ }^{46}$ Risperidone is metabolized primarily by cytochrome P450 2D6 (CYP2D6) into the active metabolite 9-hydroxyrisperidone. ${ }^{47}$ It has been believed that 9-hydroxyrisperidone had similar pharmacological activities with respect to risperidone; ${ }^{48}$ however, recent reports suggested a different hypothesis that pharmacological activity of 9-hydroxyrisperidone might not be the same as that of risperidone. The hypothesis indicated that risperidone may be more potent and subsequently more toxic than 9-hydroxyrisperidone ${ }^{49}$ The totality of plasma risperidone and 9-hydroxyrisperidone levels has been stated as the total plasma active moiety, contributing to the overall therapeutic effect. ${ }^{50} \mathrm{In}$ terms of both efficacy and toxicity, genetic factors are generally supposed to contribute to variable treatment response. ${ }^{51}$ Genetic CYP2D6 polymorphism might display a high degree of interindividual variability on clinical outcome and steady state of plasma risperidone and 9-hydroxyrisperidone levels. ${ }^{52}$

The role of CYP2D6 polymorphisms had been extensively reported, despite the differences in pharmacokinetics, adverse events, and clinical outcome. ${ }^{29,53-55}$ The $C Y P 2 D 6^{*} 1,{ }^{*} 2, * 33$, and *35 alleles have normal enzymatic activity. CYP2D $6 * 10$ and $* 41$ have reduced enzymatic activity, whereas $C Y P 2 D 6 * 3$, $* 4$, and $* 5$ have no enzymatic activity. ${ }^{29,55}$ It was consequently reported that CYP2D6 genotyping could be useful for assessing risperidone levels. ${ }^{56} \mathrm{PMs}$ had greater risperidone and total active moiety levels and lower 9-hydroxyrisperidone levels. ${ }^{57}$ The study from healthy Chinese found that people who carry CYP2D $6 * 10 / * 10$ had significantly higher levels of risperidone and risperidone/9-hydroxyrisperidone ratio than those noncarriers. ${ }^{58}$ The previous study in Autism spectrum disorders (ASD) children treated with risperidone reported that risperidone and risperidone/9-hydroxyrisperidone ratio of plasma levels was significantly higher in patients with PMs ( $p=0.03$ and $p=0.02) .{ }^{59}$ The study in Thai ASD children and adolescents found that risperidone was significantly higher in patients with $C Y P 2 D 6^{*} 5 / * 10(p=0.02), C Y P 2 D 6^{*} 10 /{ }^{*} 10$ $(p=0.04)$, and $C Y P 2 D 6 * 10 / * 41(p=0.04)$. However, there was no significant effect of CYP2D6 polymorphisms on plasma concentrations of 9-hydroxyrisperidone total active moiety. ${ }^{26}$ Vanwong et $\mathrm{a}^{25}$ found that IM patients had higher levels of risperidone and risperidone/9-hydroxyrisperidone than EM patients ( $p=0.001$ and $p<0.0001$, respectively). Moreover, the risperidone and risperidone/9-hydroxyrisperidone ratio levels in the group with CYP2D6 AS 0.5 were significantly higher than the group with the CYP2D6 AS 2.0 ( $p=0.004$ and $p=0.002$, respectively). ${ }^{25}$ Other studies in CYP2D6 polymorphism on risperidone level were shown in Table 5.

An extensive study has been performed to clarify the genetic basis of the response to risperidone in order to reduce its adverse effects. ${ }^{49}$ The CYP2D6 genotype is an important factor for clinical treatment outcome. The dopamine 


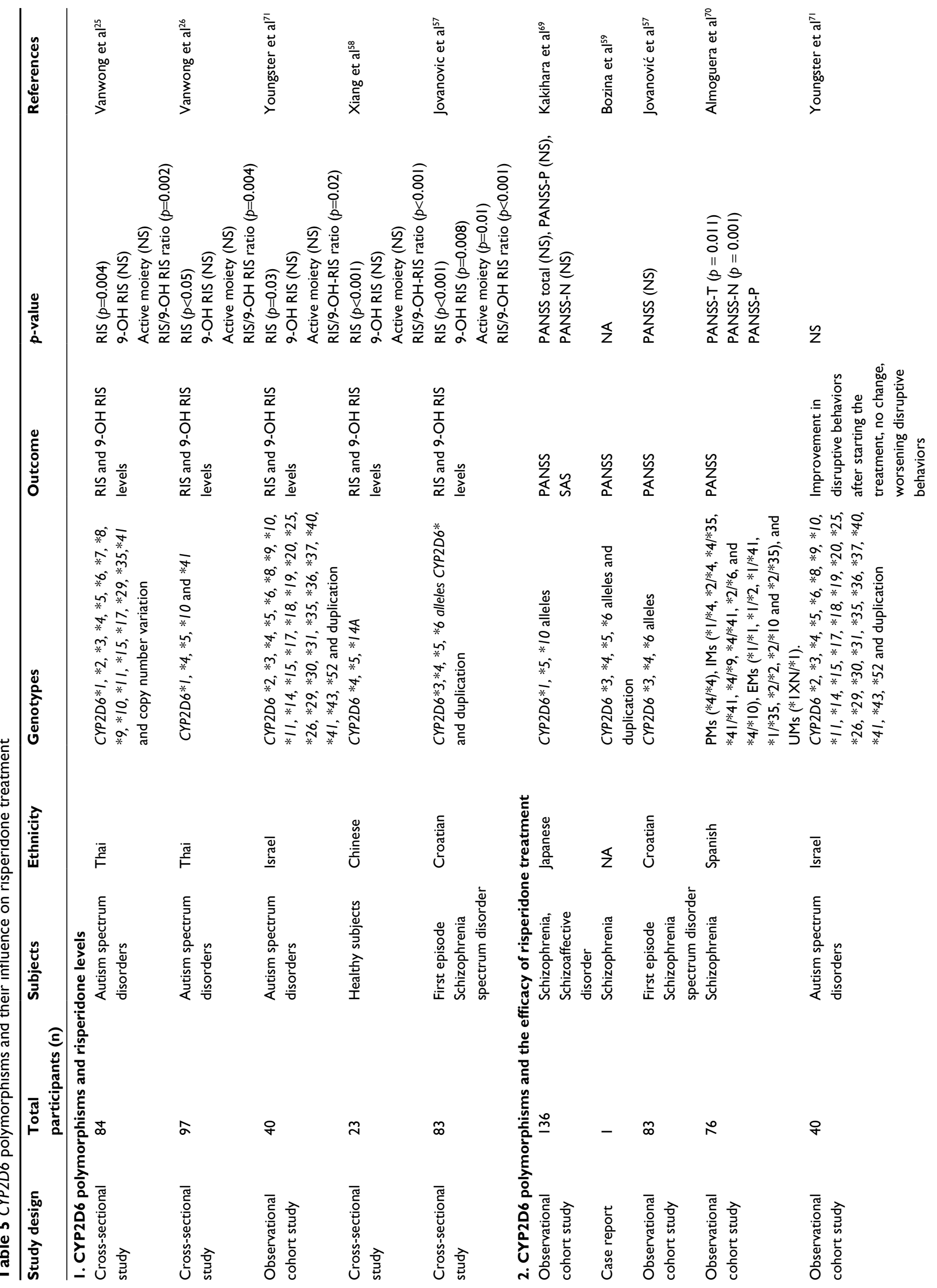




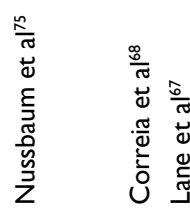

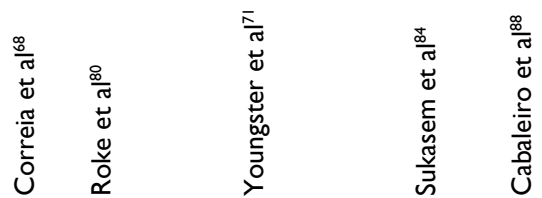

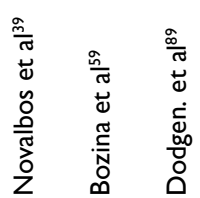

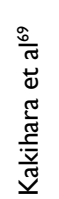

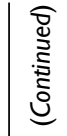

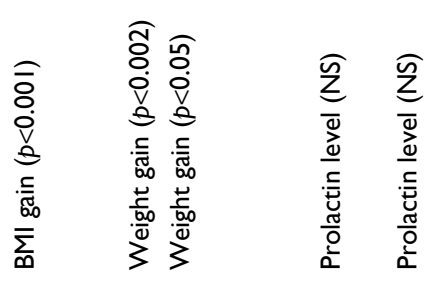

$\frac{\sqrt{\bar{L}}}{\frac{\pi}{0}}$

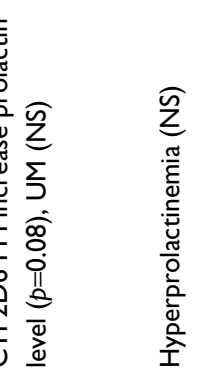

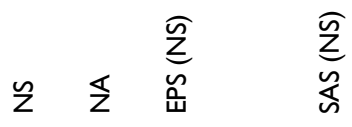

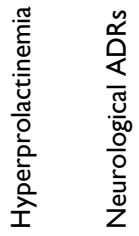



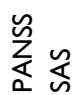

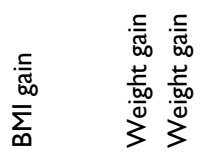

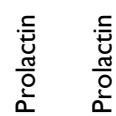

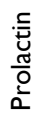

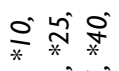

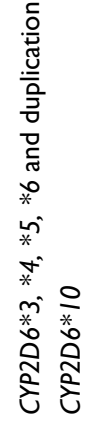

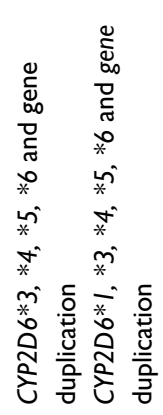

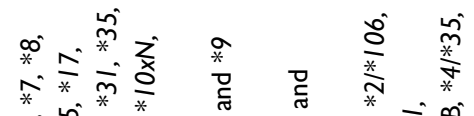

¥๐ิ

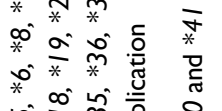

* *

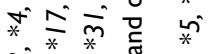

की



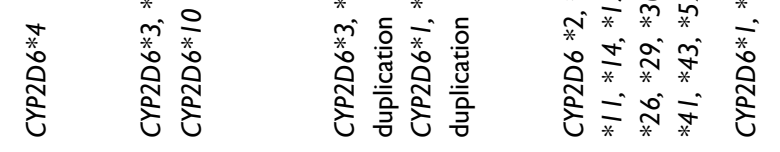

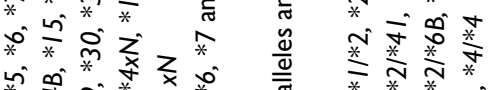





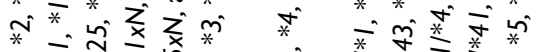

$\vec{*} * *$ *

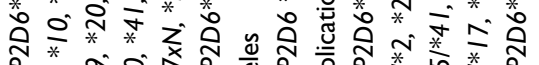

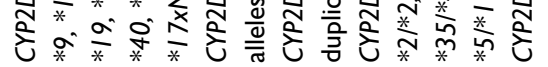

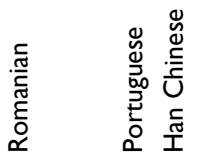

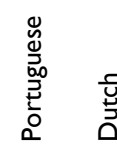

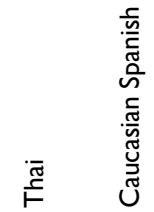



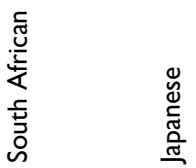
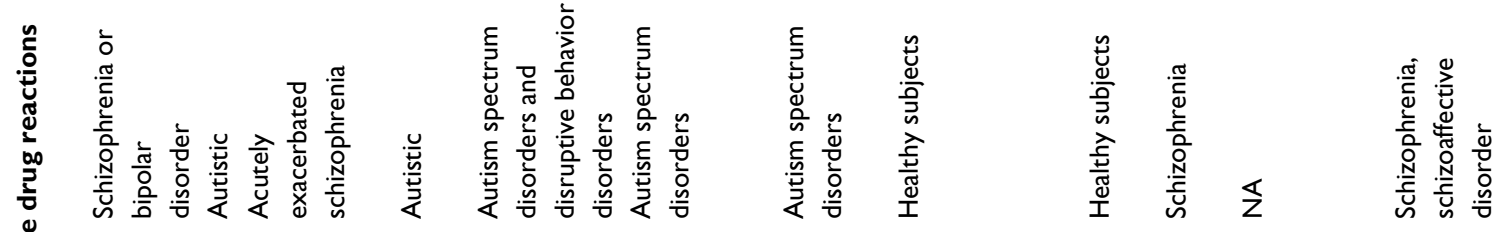

गे

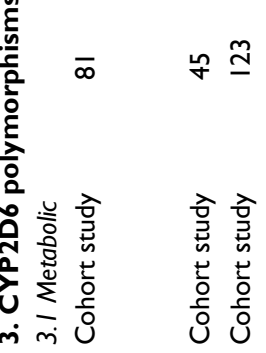
เ ร

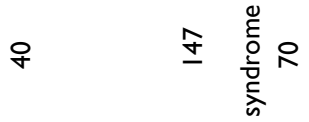

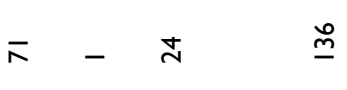
$\stackrel{\circ}{\circ}$



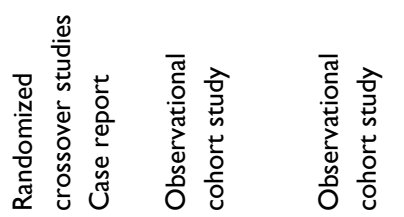

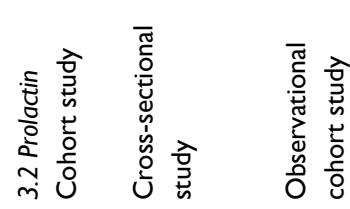






D2 receptor blockages in the anterior pituitary lead to the increasing prolactin secretion. It could be an indirect way to measure the pharmacodynamics of risperidone. Even though numerous steady-state studies have found that the plasma prolactin concentrations were significantly associated with plasma 9-hydroxyrisperidone concentrations but not with plasma risperidone concentrations, ${ }^{60-63}$ the results are inconsistent. ${ }^{64}$ Weight gain is one of the essential ADR of risperidone. ${ }^{65}$ Weight gain brings about the patient's noncompliance regardless of symptomatic improvement. ${ }^{66}$ Even though little is known about the association between weight gain and CYP2D6 polymorphisms, Lane et al reported a significant association between weight gain and $C Y P 2 D 6 * 10$ allele in risperidone-treated patients. ${ }^{67}$ Recently, Correia et al found UM to be associated with a less weight gain while on therapy when compared to the EM phenotype.$^{68}$ However, the PM phenotype showed similar effect as compared to the EM phenotype ${ }^{68}$ In conclusion, metabolism of risperidone relies on the number of active CYP2D6 alleles, and some effects might be more common in the group of PMs. The findings proposed that the determination of an accurate CYP2D6 genotype-predicted phenotype is necessary in the clinical setting and individualization of drug therapy.

\section{Impact of CYP2D6 genetic variation on the efficacy of risperidone treatment}

CYP2D6 variations have a major effect on the pharmacokinetics of risperidone. Thus, the genetic variation of this gene plays a role in the efficacy of risperidone treatment. Risperidone had been used in many psychiatric diseases. Several pharmacogenetic studies showed the effect of CYP2D6 variation in the treatment outcomes. However, there are controversial results for CYP2D6 and risperidone efficacy. Several out of date studies showed no correlation of CYP2D6 variation with risperidone treatment outcome.

A study of 136 patients who were diagnosed with schizophrenia, schizoaffective disorder, delusional disorder, and brief psychotic disorder and treated with risperidone single regimen showed no association between CYP2D6 polymorphism and clinical improvement results. Clinical improvement was evaluated using Positive and Negative Syndrome Scale (PANSS). Patients were genotyped as CYP2D6 $* 1 / * 1(\mathrm{n}=16)$, $* 1 / * 10(\mathrm{n}=14)$, and $* 10 / * 10(\mathrm{n}=9)$. There were no differences in the clinical improvement among CYP2D6 genotype in this study. Moreover, there was no correlation between the active moiety plasma concentrations (risperidone and 9-hydroxyrisperidone) and the percentage improvement of 
total PANSS-Positive or PANSS-Negative scores. This study mentions the plasma concentration of active moiety that might play a role only in the extrapyramidal adverse reaction. ${ }^{69}$

One case report of a woman with schizophrenia who was treated with risperidone and followed up for 1 year also showed no significant association of CYP2D6 genotype and clinical outcome. The patient was genotyped as CYP2D6 *4/*6 and classified as PM. The PANSS score showed stable remission of illness over the stated period. Thus, PM phenotype of CYP2D6 in this patient does not have a significant effect in clinical symptoms. ${ }^{59}$ Similarly, the improvement of symptoms in 83 schizophrenia patients was not related to variations in $C Y P 2 D 6$ and risperidone concentration data. The CYP2D6 genotype was determined as *3, *4, and *6 alleles, and then grouped to CYP2D6 wt/wt, wt/mut, and mut/ $m u t$. Patients showed significant improvements in positive and general symptoms, but not associated with genetic variations which were classified in this study. ${ }^{57}$

On the contrary, a recent study ${ }^{70}$ indicated the significant association of $C Y P 2 D 6$ polymorphism and risperidone clinical improvement. Changes in PANSS total (PANSS-T), negative (PANSS-N), and positive (PANSS-P) scales were measured in risperidone-treated schizophrenic patients. If the changes of PANSS score were $>50 \%$, the patients were grouped as responders. The number of patients responding with treatment was evaluated with CYP2D6 genotype. Predicted phenotypes were classified as PMs $(* 4 / * 4)$, IMs $(* 1 / * 4, * 2 / * 4, * 4 / * 35, * 41 / * 41, * 4 / * 9, * 4 / * 41, * 2 / * 6$, and $* 4 / * 10)$, EMs $(* 1 / * 1, * 1 / * 2, * 1 / * 41, * 1 / * 35, * 2 / * 2, * 2 / * 10$, and $* 2 / * 35)$, and UMs $(* 1 \mathrm{XN} / * 1)$. CYP2D6 PMs showed a statistically significant clinical improvement in PANSS-T compared with EMs $(66.7 \%$ vs $8.1 \%, p=0.011)$. The sample size of this study was too small. However, the power was enough to find an association with PANSS-T improvement. This study investigated many CYP2D6 alleles and grouped into different metabolizer phenotypes according to the AS, which decrease the misclassifications. ${ }^{70}$

The other observational cohort study of children with autistic disorder, pervasive developmental disorder not otherwise specified, or Asperger syndrome who were treated with risperidone for at least 3 months showed the association of CYP2D6 polymorphism with clinical response. Patients who had any combination of the null alleles $(* 3, * 4, * 5$, $* 6$, *52, or *4xn) were classified as PM. Patients with one nonfunctional CYP2D6 null allele $(* 3, * 4, * 5, * 6, * 52, * 4 x n)$ and one low activity $C Y P 2 D 6$ allele $(* 9, * 10, * 29, * 41)$ were grouped as IMs, patients with one or two functional copies of the $C Y P 2 D 6$ gene were grouped as EMs. Clinical outcomes were determined by asking the parents to grade the child's clinical response to treatment as improvement in disruptive behaviors after starting the treatment, no change, or worsening disruptive behaviors. The result showed that two PM patients were responders but had ADRs. In contrast, two patients were CYP2D6 UMs and nonresponders and had no ADRs. Risperidone or its metabolite plasma levels did not show the difference in responders and nonresponders, or when comparing patients with or without ADRs. However, the results did not show the statistically significant difference due to small sample size. ${ }^{71}$

Although previous studies found the significant difference of risperidone and 9-hydroxyrisperidone between CYP2D6 PMs and IMs or EMs, the total active moiety did not change too much between each phenotype groups. Therefore, the efficacy of risperidone may not be altered by $C Y P 2 D 6$ polymorphism. There is no clarified study to determine the significant effect of CYP2D6 variations with risperidonetreated clinical outcomes. The novel technic to detect several $C Y P 2 D 6$ gene variations should be used to limit the misclassification of CYP2D6 genotype. Moreover, suitable guideline to predict the phenotype should be applied to determine the activity of this enzyme. The precise classification of CYP2D6 genotype and prediction of phenotype might lead to accurate study results. Furthermore, large sample size will increase the power of analysis and show the clarified result. Other studies in CYP2D6 polymorphism on the efficacy of risperidone treatment were listed in Table 5.

\section{The consequence of CYP2D6 polymorphisms in risperidone- associated ADRs Metabolic}

The exact mechanism of risperidone-related metabolic adverse effects is inconclusive. Not all the patients treated with risperidone had metabolic adverse effects. This high interindividual variability in the risk of metabolic adverse effects proposed that genetics might play an essential role in a person's susceptibility to metabolic adverse effects, making it a target for pharmacogenetics studies.

Pharmacokinetic gene variation may be associated with the metabolism and disposition of risperidone. An individual's genetic variations might have an impact on the metabolism and disposition including safety, tolerability, and efficacy of the risperidone. One of the most important genetic factors influencing risperidone pharmacokinetics is phase I metabolism mediated predominantly by $C Y P 2 D 6 .{ }^{72}$ Since the antipsychotic drugs were metabolized by CYP2D6 enzymes, individuals with the PM-predicted phenotype 
might suffer from dose-dependent complications because of increased plasma levels and result in serious toxicity of antipsychotic drugs. ${ }^{73}$ Moreover, the CYP2D6 PM phenotype was stated to relate with risperidone side effects and result in discontinuation. ${ }^{74}$ Weight gain is one of the most important ADRs of risperidone. ${ }^{65}$ Weight gain causes reduced patient compliance irrespective of symptomatic improvement. ${ }^{66}$ According to the CYP2D6 genotype, Nussbaum et al noted that the patients with $* 1 / * 4$ genotype (IM phenotype) had significantly higher weight gain values than the patients who did not carry allele $* 4$, study in child and adolescent being on treatment with antipsychotics (risperidone, aripiprazole, or olanzapine). ${ }^{75}$ Vicki et al reported that the patient treated with AAP which was $C Y P 2 D 6 * 1 / * 3$ or $* 4$ genotype undergoing a larger percent body mass index change significant $(p<0.0097)$ than those with a ${ }^{*} 1 / * 1$ genotype. ${ }^{76}$ Lane et al found a significant association between the CYP2D6*10 allele and weight gain in patients with risperidone treatment. ${ }^{67}$ The findings propose that this might be due to high concentrations of risperidone resulting in increased exposure, which may trigger risperidone-induced weight gain and metabolic effect. The CYP2D6 genotype in children and adolescents might be a good predictor for the response to risperidone, and the side effects could be registered. Therefore, screening of pharmacogenetics is necessary in future clinical practice, allowing for personalized treatment, especially for at-risk individuals such asmetabolic.

\section{Prolactin}

Elevation of serum prolactin is an indicator of dopamine receptor blockade at the level of the anterior pituitary lactotroph cells in the tuberoinfundibular pathway of the brain. A reduction in dopaminergic signaling pathway to the lactotroph cells results in a rapid increase in prolactin secretion. Such a reduction in dopamine can occur through the administration of antipsychotics. Among all AAPs, risperidone was reported to have high prevalence of hyperprolactinemia. ${ }^{77}$ Several pediatric population studies in patients who were treated with risperidone account for $45 \%-70 \%$ of high incidence of hyperprolactinemia. ${ }^{78-82}$

Variation in the highly polymorphic CYP2D6 was associated with risperidone-increased prolactin. A previous study has discovered the association between prolactin concentrations and CYP2D6 polymorphisms of autism children receiving risperidone. An observational study of long-term risperidone evaluated prolactin response modified by $C Y P 2 D 6$ among 47 children and adolescents aged 10-19 years with autism spectrum disorders or disruptive behavior disorders. ${ }^{80}$ This study described that the number of patients with hyperprolactinemia was $100 \%(2 / 2)$ for CYP2D6 PM, $47 \%$ (8/17) for CYP2D6 IM, 48\% (12/25) for CYP2D6 EM, and no one $(0 / 2)$ in CYP2D6 UM. A possible hypothesis may explain the interactions of 5-methoxytryptamine (5MT), CYP2D6, serotonin, and dopamine systems in relation to prolactin release from the pituitary. ${ }^{83}$ With the properties of CYP2D6 PM, deficient metabolized function may potentially display diminished serotonin reproduction from 5MT. As a result, this can lead to a higher dopamine tone in the anterior pituitary because serotonin generally exerts a tonic inhibitory effect on dopamine pathways. Consequently, after treatment with dopamine antagonist such as risperidone or perphenazine, a prolactin response could be noticed in CYP2D6 PM.

However, the effects of the CYP2D6 genetic polymorphisms on serum prolactin concentration are still controversial. This may relate to differences in methodology (e.g., retrospective and prospective open-label studies as well as case-control studies) or small sample size. ${ }^{68,71}$ There is also a possibility for ethnic differences in genetic polymorphisms of CYP2D6. The CYP2D6 PM phenotype in Asians is less frequent than that in Caucasians (e.g., $\sim 1 \%$ in Thai, Chinese, and Japanese populations versus $5 \%-10 \%$ in Caucasians). ${ }^{84,85}$

The Canadian Alliance for Monitoring Effectiveness and Safety of Antipsychotics in Children (CAMESA) guideline group ${ }^{86}$ suggested that prolactin monitoring is recommended after 3 months of risperidone or other antipsychotics treatment and, if normal, on a yearly basis thereafter in asymptomatic children. The strongest predictors of hyperprolactinemia are the type and dose of the antipsychotic prescribed, such as risperidone, with increased levels observed at higher doses ${ }^{81}$ along with plasma concentrations of 9-hydroxyrisperidone. ${ }^{63}$ Although most of the studies have not exhibited an association between prolactin levels and adverse effects such as amenorrhea, galactorrhea, or gynecomastia, prolactinassociated adverse effects can occur with levels between 50 and $100 \mathrm{ng} / \mathrm{mL} .{ }^{87}$ Moreover, if amenorrhea has lasted for 12 months or longer in patients on antipsychotics, bone mineral density measurements should also be undertaken. Therefore, pharmacogenetic screening of hyperprolactinemia and regular monitoring of prolactin before and during treatment will help prevent those developing antipsychotic-induced hyperprolactinemia.

\section{Extrapyramidal syndrome}

Neurological and extrapyramidal adverse effects (EPS) are the adverse effects of risperidone which were evaluated with CYP2D6 polymorphism in several studies. However, 
the impact of CYP2D6 on EPS from risperidone is unclear. Although several studies showed no significant difference of EPS among CYP2D6 variation, some of them showed a borderline significant trend. Two studies in healthy volunteers showed no association between CYP2D6 polymorphism and adverse effects. The adverse effects of risperidone in 70 healthy volunteers were reported in this study. The most frequent adverse effects were neurological (somnolence (47.1\%), headache (21.4\%), and dizziness (17.1\%)). In several genes, polymorphisms were associated with neurological adverse effects (CYP2C9, NAT2, AGTR1, DRD2, $C Y P 2 C 19$, and $C Y P 2 C 9$ ) and psychiatric effects (CYP2C9 and $H T R 2 A)$. However, there is no association between $C Y P 2 D 6$ polymorphism and any adverse effects. ${ }^{88}$ Other CYP2D6 and risperidone studies on healthy volunteers also showed no significant difference of adverse effects among CYP2D6-predicted phenotype. ${ }^{39}$ Even though the incidence of adverse effects was lower in the PMs (50\%) than IMs (84\%), EMs (73.5\%), and UMs (83.3\%), there is no significant difference. The similarity of risperidone and its active metabolite may cause the same adverse effect between each CYP2D6 phenotype groups. ${ }^{39}$

One case report showed no adverse effects in schizophrenic patients who were treated with risperidone and showed no association with CYP2D6 polymorphism. Although risperidone concentrations in this case were higher than normal, patients did not experience the toxicity of risperidone. The researchers hypothesized that the alternative metabolic pathway $(C Y P 3 A)$ might play a role in risperidone metabolism. ${ }^{59}$ In a cohort study, 24 South African risperidonetreated patients presented movement disorders and weight gain adverse reactions from risperidone. The most common ADR is parkinsonism followed by dyskinesia. However, there is no statistically significant association between CYP2D6 poor metabolism and risperidone ADRs. ${ }^{89}$ Other studies ${ }^{69}$ assessed extrapyramidal symptoms of patients using Simpson and Angus Scale (SAS) 2 weeks after the administration of risperidone. Even though the active moiety was positively correlated with SAS score, there were no differences in this score among CYP2D6 genotypes. Because the active moiety was not different in each CYP2D6 genotypes, CYP2D6 polymorphism may not affect extrapyramidal symptoms in this study. ${ }^{69}$ Similar to the previous study, there were no association of reported side effects (neurologic, cardiovascular, psychic, and sexual side effects) with CYP2D6-predicted phenotype. Only minimum active moiety concentration was found to be associated with neurologic symptoms, especially the severity of tremor. ${ }^{90}$ However, one study showed a trend of the association between CYP2D6 PM phenotype and the presence of tardive dyskinesia (TD). The result showed that a number of patients who had TD in CYP2D6 PMs and non-PMs were 43\% (16/38) and 31\% (146/352), respectively. But, there was no significant difference between the two groups (odds ratio $(\mathrm{OR})=1.7$, confidence interval $(\mathrm{CI})=$ $0.84-3.2, p=0.14)$. Total risperidone duration was limited for PMs in this study. Only 79\% (28/38) took risperidone for $>6$ months, and only $26 \%$ (10/38) for $>1$ year. Thus, even many patients who were exposed to risperidone for a very short duration developed TD. ${ }^{91}$

Little publication showed the association between risperidone-induced movement disorders and CYP2D6 polymorphisms. The majority indicated no association, but some study showed a trend of correlation. One study showed the association of CYP2D6 polymorphisms with EPS ADRs. There were 73 patients with moderate to severe ADRs in risperidone-taking group and 81 patients with ADRs who discontinued from risperidone group. EPS (resting tremor, stiffness, hypersalivation, and akathisia) was the most common ADR in both risperidone group (92\%, 67/73) and discontinued from risperidone group (57\%, 46/81). The other frequent ADRs were sedation and sexual problem. The CYP2D6 PM phenotype was associated with risperidone ADRs in patients who take risperidone $(\mathrm{OR}=3.4$; CI $=1.5-8.0, p=0.004)$ and patients who discontinued from risperidone $(\mathrm{OR}=6 ; \mathrm{CI}=1.4-25.4, p=0.02)$ after adjusting the confounding factor by multivariate analysis. ${ }^{74}$ Although a significant association was found in this study, the small sample size of CYP2D6 PMs was a concern. Many previous studies that found the association of CYP2D6 polymorphisms with risperidone ADR were shown in Table 5. Moreover, pharmacodynamic gene variations may play a greater role for risperidone ADRs. A further large prospective study should analyze both $C Y P 2 D 6$ polymorphism and pharmacodynamic gene variations together to find the significant association.

\section{Challenges, opportunities, and future directions in the clinical application of genomic profiling in CYP2D6}

From the previous study, CYP2D6 phenotypes have been classified into 4 classes of enzyme activities according to the predicted phenotype model, ${ }^{55,92}$ which can help to estimate the patient response. However, the IM phenotype consists of various genotype subgroups, and it might have an influence on the variation in CYP2D6 enzyme activity within 
this group. Stingl et al noted that CYP2D6 IM phenotypes are carriers either of 1 normal allele +1 nonfunctional allele (*1/def), 1 nonfunctional allele +1 reduced-function allele (def/red), or 2 reduced function alleles (red/red).${ }^{93}$ Hendset et al reported that the $\mathrm{def} / \mathrm{red}$ and $\mathrm{red} / \mathrm{red}$ genotypes have 4.5fold and 3.4-fold higher serum concentration of risperidone compared with $* 1 /$ def genotype. ${ }^{94}$ It means that there was a considerable variability in risperidone plasma concentration between $C Y P 2 D 6$ intermediate genotype which carries 2 variant alleles or more than 1 variant allele. Moreover, Rau et al noted that patients with PM phenotype showed a 3-fold increased risk of ADR compare with EMs. Various enzyme activities are found in both the same phenotype subgroup and in the different phenotype subgroup.

According to the interindividual response, almost all the physicians adjust the daily dose of risperidone according to the clinical response of the patients. Therapeutic drug monitoring (TDM) is an important tool for therapeutic optimization, dosage assessment, and complementation in clinical treatment. Moreover, TDM can explain either the adverse effects or the responsiveness in patients treated with the drug that has a narrow therapeutic index or multiple medications. Therefore, TDM plays a crucial role in pharmacogenetic tests in order to optimize the dose of an individual patient. ${ }^{95}$

In natural setting, coprescription of drugs that belong to different classes is normal, especially in elderly patients. Patients who were treated with more multiple medication show more multidrug interactions. Generally, risperidone has been coprescribed not only with antidepressants and antiepileptics but also with other drugs in antipsychotics. The direct mechanistic evidence for the kinetics of drug-drug interaction in both 2-drug interaction and interactions of several drugs in combination has been studied. ${ }^{96-98}$

Mannheimer et al reported that the risperidone concomitance with CYP2D6 substrate drug did not have impact on the level of risperidone and 9-hydroxyrisperidone. It means that the risk of drug-drug interaction of CYP2D6 substrate is low in comedication. In addition, either a strong CYP2D6 inhibitors, bupropion, or a moderate CYP2D6 inhibitor, sertraline, will affect the serum concentration of risperidone, but no influence on 9-hydroxyrisperidone serum concentration. ${ }^{99}$ The comedication of CYP2D6 inducer, rifampin, significantly decreased $51 \%$ of risperidone, $43 \%$ of 9 -hydroxyrisperidone, and $45 \%$ of the active moieties of the mean area under curve. ${ }^{100}$ In addition, the antiepileptic, carbamazepine decreases 50\% of plasma concentration of both risperidone and its active metabolite. ${ }^{101}$ As a result, the information regarding drug-drug interaction in CYP2D6 enzyme response may help in predicting and avoiding the clinical efficacy or toxicity.
There are several publications about the correlation among CYP2D6 genotype, CYP2D6 enzyme activity, adverse events, and treatment outcome and risperidone therapy. This knowledge is very useful in terms of personalized medication. The dose recommendations of risperidone according to CYP2D6 polymorphisms are an interesting study. A case-control study found that CYP2D6 PMs had a 3-fold increase in the risperidone ADR than EM patients. ${ }^{102}$ The study published a case report of a patient with schizophrenia who was treated with risperidone for 1 year. She was identified as a CYP2D6 PM, and it was expected that she might have an accumulation of risperidone and influence on significant side effect. The plasma risperidone and 9-hydroxyrisperidone concentration were monitored, and the result showed the therapeutic index. Stable symptoms and no adverse effects were observed. Bozina et al suggested that CYP2D6 PM phenotype might not have an influence on the clinical significance of risperidone treatment because other pathways were metabolized risperidone. ${ }^{59}$

From the results of this research study, it is inferred that many factors influence risperidone metabolism. The challenge to use genetic-based treatment corresponds to many factors that affect the efficacy and toxicity. However, the questions as to what amount of dose should be adjusted for the dose regimens still remains. Steimer et al recommended the semiquantitative gene dose (SGD) system to apply geneticbased dose recommendation. ${ }^{103}$ The amount of adjustment was calculated from the difference in mean concentration of each SGD group compared to the mean concentration of the total population. However, this study was performed in amitriptyline and the active metabolite. ${ }^{104}$ Another strategy for dose adjustment is suggested by Kirchheiner et al who used the ratio of concentration in EM group as a reference group and that of other genotype groups to calculate the recommended dose for each individual group. Fifty percent dose reduction was recommended for PM of CYP2D6 substrates. ${ }^{105}$ Using a population pharmacokinetic approach is a strategy to find out a suitable risperidone dosage. Vandenberghe et al reported that $C Y P 2 D 6$ but not NR1/2, POR, PPAR $\alpha$, $A B C B 1, C Y P 3 A$ plays an important role in risperidone, 9-hydroxyrisperidone, and active moiety plasma concentration. ${ }^{90}$ However, the CYP2D6 metabolizer subpopulation into PM, EM, IM, UM should be analyzed. From this result, it is found that $C Y P 2 D 6$ is a major factor to provide a guideline for genotype-based dose recommendation.

\section{Acknowledgment}

The research results in this review article were derived from the research projects which were supported by Khun Poom Foundation, a project under Her Royal Highness Princess 
Ubonratana Rajakanya Siriwatana Bhanawadee and The National Research Council of Thailand.

\section{Disclosure}

The authors report no conflicts of interest in this work.

\section{References}

1. Correll CU. Antipsychotic polypharmacy, Part 2: why use 2 antipsychotics when 1 is not good enough? J Clin Psychiatry. 2008;69(5):860-861.

2. Hong CJ, Liou YJ, Bai YM, Chen TT, Wang YC, Tsai SJ. Dopamine receptor D2 gene is associated with weight gain in schizophrenic patients under long-term atypical antipsychotic treatment. Pharmacogenet Genomics. 2010;20(6):359-366.

3. Lane HY, Lee CC, Liu YC, Chang WH. Pharmacogenetic studies of response to risperidone and other newer atypical antipsychotics. Pharmacogenomics. 2005;6(2):139-149.

4. Wang JS, Ruan Y, Taylor RM, Donovan JL, Markowitz JS, DeVane $\mathrm{CL}$. The brain entry of risperidone and 9-hydroxyrisperidone is greatly limited by P-glycoprotein. Int J Neuropsychopharmacol. 2004;7(4) 415-419.

5. Doran A, Obach RS, Smith BJ, et al. The impact of P-glycoprotein on the disposition of drugs targeted for indications of the central nervous system: evaluation using the MDR1A/1B knockout mouse model. Drug Metab Dispos. 2005;33(1):165-174

6. Fang J, Bourin M, Baker GB. Metabolism of risperidone to 9-hydroxyrisperidone by human cytochromes P450 2D6 and 3A4. Naunyn Schmiedebergs Arch Pharmacol. 1999;359(2):147-151.

7. Brunton PJ, Donadio MV, Russell JA. Sex differences in prenatally programmed anxiety behaviour in rats: differential corticotropin-releasing hormone receptor mRNA expression in the amygdaloid complex. Stress. 2011;14(6):634-643.

8. Masri B, Salahpour A, Didriksen M, et al. Antagonism of dopamine D2 receptor/beta-arrestin 2 interaction is a common property of clinically effective antipsychotics. Proc Natl Acad Sci U S A. 2008; 105(36):13656-13661.

9. Ito $\mathrm{H}$, Takano $\mathrm{H}$, Takahashi $\mathrm{H}$, et al. Effects of the antipsychotic risperidone on dopamine synthesis in human brain measured by positron emission tomography with L-[beta-11C]DOPA: a stabilizing effect for dopaminergic neurotransmission? J Neurosci. 2009;29(43):13730-13734.

10. Abou El-Magd RM, Park HK, Kawazoe T, et al. The effect of risperidone on D-amino acid oxidase activity as a hypothesis for a novel mechanism of action in the treatment of schizophrenia. J Psychopharmacol. 2010;24(7):1055-1067.

11. Bymaster FP, Calligaro DO, Falcone JF, et al. Radioreceptor binding profile of the atypical antipsychotic olanzapine. Neuropsychopharmacology. 1996;14(2):87-96.

12. Richelson E, Souder T. Binding of antipsychotic drugs to human brain receptors focus on newer generation compounds. Life Sci. 2000;68(1):29-39.

13. Heim MH, Meyer UA. Evolution of a highly polymorphic human cytochrome P450 gene cluster: CYP2D6. Genomics. 1992;14(1):49-58.

14. Eichelbaum M, Baur MP, Dengler HJ, et al. Chromosomal assignment of human cytochrome P-450 (debrisoquine/sparteine type) to chromosome 22. Br J Clin Pharmacol. 1987;23(4):455-458.

15. Zanger UM, Raimundo S, Eichelbaum M. Cytochrome P450 2D6: overview and update on pharmacology, genetics, biochemistry. Naunyn Schmiedebergs Arch Pharmacol. 2004;369(1):23-37.

16. Kimura S, Umeno M, Skoda RC, Meyer UA, Gonzalez FJ. The human debrisoquine 4-hydroxylase (CYP2D) locus: sequence and identification of the polymorphic CYP2D6 gene, a related gene, and a pseudogene. Am J Hum Genet. 1989;45(6):889-904.

17. Hicks JK, Bishop JR, Sangkuhl K, et al. Clinical Pharmacogenetics Implementation Consortium (CPIC) guideline for CYP2D6 and CYP2C19 genotypes and dosing of selective serotonin reuptake inhibitors. Clin Pharmacol Ther. 2015;98(2):127-134.
18. Lien EA, Solheim E, Lea OA, Lundgren S, Kvinnsland S, Ueland PM. Distribution of 4-hydroxy-N-desmethyltamoxifen and other tamoxifen metabolites in human biological fluids during tamoxifen treatment. Cancer Res. 1989;49(8):2175-2183.

19. Crews KR, Gaedigk A, Dunnenberger HM, et al. Clinical Pharmacogenetics Implementation Consortium guidelines for cytochrome P450 2D6 genotype and codeine therapy: 2014 update. Clin Pharmacol Ther. 2014;95(4):376-382.

20. Hosono N, Kato M, Kiyotani K, et al. CYP2D6 genotyping for functional-gene dosage analysis by allele copy number detection. Clin Chem. 2009;55(8):1546-1554.

21. Kiyotani K, Shimizu M, Kumai T, Kamataki T, Kobayashi S, Yamazaki H. Limited effects of frequent CYP2D6*36-*10 tandem duplication allele on in vivo dextromethorphan metabolism in a Japanese population. Eur J Clin Pharmacol. 2010;66(10):1065-1068.

22. Chamnanphon M, Pechatanan K, Sirachainan E, et al. Association of CYP2D6 and CYP2C19 polymorphisms and disease-free survival of Thai post-menopausal breast cancer patients who received adjuvant tamoxifen. Pharmacogenomics Pers Med. 2013;6:37-48.

23. Sukasem C, Sirachainan E, Chamnanphon M, et al. Impact of CYP2D6 polymorphisms on tamoxifen responses of women with breast cancer: a microarray-based study in Thailand. Asian Pac J Cancer Prev. 2012;13(9):4549-4553.

24. Suwannasri P, Thongnoppakhun W, Pramyothin P, Assawamakin A, Limwongse C. Combination of multiplex PCR and DHPLC-based strategy for CYP2D6 genotyping scheme in Thais. Clin Biochem. 2011;44(13):1144-1152.

25. Vanwong N, Ngamsamut N, Hongkaew Y, et al. Detection of CYP2D6 polymorphism using Luminex XTAG technology in autism spectrum disorder: CYP2D6 activity score and its association with risperidone levels. Drug metab pharmacokinet. 2016;31(2):156-162.

26. Vanwong N, Ngamsamut N, Medhasi S, et al. Impact of CYP2D6 polymorphism on steady-state plasma levels of risperidone and 9-hydroxyrisperidone in Thai children and adolescents with autism spectrum disorder. J Child Adolesc Psychopharmacol. Epub 2016 Jan 18.

27. International Breast Cancer Study Group, Colleoni M, Gelber S, et al. Tamoxifen after adjuvant chemotherapy for premenopausal women with lymph node-positive breast cancer: International Breast Cancer Study Group Trial 13-93. J Clin Oncol. 2006;24(9):1332-1341.

28. Sistonen J, Sajantila A, Lao O, Corander J, Barbujani G, Fuselli S. CYP2D6 worldwide genetic variation shows high frequency of altered activity variants and no continental structure. Pharmacogenet Genomics. 2007;17(2):93-101.

29. Zhou SF. Polymorphism of human cytochrome P450 2D6 and its clinical significance: part I. Clin Pharmacokinet. 2009;48(11):689-723.

30. Londin ER, Clark P, Sponziello M, Kricka LJ, Fortina P, Park JY. Performance of exome sequencing for pharmacogenomics. Per Med. 2014;12(2):109-115.

31. Affymetrix. Available from: http://www.affymetrix.com. Accessed June 4, 2016.

32. Database THCPCAN. Available from: http://www.cypalleles.ki.se/ cyp2d6.htm. Accessed June 2, 2016

33. Ingelman-Sundberg M, Sim SC, Gomez A, Rodriguez-Antona C. Influence of cytochrome $\mathrm{P} 450$ polymorphisms on drug therapies: pharmacogenetic, pharmacoepigenetic and clinical aspects. Pharmacol Ther. 2007;116(3):496-526.

34. Stearns V, Johnson MD, Rae JM, et al. Active tamoxifen metabolite plasma concentrations after coadministration of tamoxifen and the selective serotonin reuptake inhibitor paroxetine. $J$ Natl Cancer Inst. 2003;95(23):1758-1764.

35. Hertz DL, Snavely AC, McLeod HL, et al. In vivo assessment of the metabolic activity of CYP2D6 diplotypes and alleles. Br J Clin Pharmacol. 2015;80(5):1122-1130.

36. Dalen P, Dahl ML, Bernal Ruiz ML, Nordin J, Bertilsson L. 10-Hydroxylation of nortriptyline in white persons with $0,1,2,3$, and 13 functional CYP2D6 genes. Clin Pharmacol Ther. 1998;63(4):444-452.

37. Mellstrom B, Bertilsson L, Sawe J, Schulz HU, Sjoqvist F. E- and Z-10-hydroxylation of nortriptyline: relationship to polymorphic debrisoquine hydroxylation. Clin Pharmacol Ther. 1981;30(2):189-193. 
38. Bertilsson L, Eichelbaum M, Mellstrom B, Sawe J, Schulz HU, Sjoqvist F. Nortriptyline and antipyrine clearance in relation to debrisoquine hydroxylation in man. Life Sci. 1980;27(18):1673-1677.

39. Novalbos J, Lopez-Rodriguez R, Roman M, Gallego-Sandin S, Ochoa D, Abad-Santos F. Effects of CYP2D6 genotype on the pharmacokinetics, pharmacodynamics, and safety of risperidone in healthy volunteers. $J$ Clin Psychopharmacol. 2010;30(5):504-511.

40. Sakuyama K, Sasaki T, Ujiie S, et al. Functional characterization of 17 CYP2D6 allelic variants (CYP2D6.2, 10, 14A-B, 18, 27, 36, 39, 47-51, 53-55, and 57). Drug Metab Dispos. 2008;36(12):2460-2467.

41. Willyard C. Copy number variations' effect on drug response still overlooked. Nat Med. 2015;21(3):206.

42. Beoris M, Amos Wilson J, Garces JA, Lukowiak AA. CYP2D6 copy number distribution in the US population. Pharmacogenet Genomics. 2016;26(2):96-99.

43. Sheng HH, Zeng AP, Zhu WX, et al. Allelic distributions of CYP2D6 gene copy number variation in the Eastern Han Chinese population. Acta Pharmacol Sin. 2007;28(2):279-286.

44. Gaedigk A, Simon SD, Pearce RE, Bradford LD, Kennedy MJ, Leeder JS. The CYP2D6 activity score: translating genotype information into a qualitative measure of phenotype. Clin Pharmacol Ther. 2008;83(2):234-242.

45. Borges S, Desta Z, Li L, et al. Quantitative effect of CYP2D6 genotype and inhibitors on tamoxifen metabolism: implication for optimization of breast cancer treatment. Clin Pharmacol Ther. 2006;80(1):61-74.

46. Janssen PA, Niemegeers CJ, Awouters F, Schellekens KH, Megens AA, Meert TF. Pharmacology of risperidone (R 64 766), a new antipsychotic with serotonin-S2 and dopamine-D2 antagonistic properties. $J$ Pharmacol Exp Ther. 1988;244(2):685-693.

47. Mannens G, Huang ML, Meuldermans W, Hendrickx J, Woestenborghs $\mathrm{R}$, Heykants J. Absorption, metabolism, and excretion of risperidone in humans. Drug Metab Dispos. 1993;21(6):1134-1141.

48. van Beijsterveldt LE, Geerts RJ, Leysen JE, et al. Regional brain distribution of risperidone and its active metabolite 9-hydroxy-risperidone in the rat. Psychopharmacology. 1994;114(1):53-62.

49. de Leon J, Sandson NB, Cozza KL. A preliminary attempt to personalize risperidone dosing using drug-drug interactions and genetics: part I. Psychosomatics. 2008;49(3):258-270.

50. Du J, Zhang A, Wang L, et al. Relationship between response to risperidone, plasma concentrations of risperidone and CYP3A4 polymorphisms in schizophrenia patients. J Psychopharmacol. 2010;24(7):1115-1120.

51. Mas S, Gasso P, Bernardo M, Lafuente A. Functional analysis of gene expression in risperidone treated cells provide new insights in molecular mechanism and new candidate genes for pharmacogenetic studies. Eur Neuropsychopharmacol. 2013;23(4):329-337.

52. Cartwright AL, Wilby KJ, Corrigan S, Ensom MH. Pharmacogenetics of risperidone: a systematic review of the clinical effects of CYP2D6 polymorphisms. Ann Pharmacother. 2013;47(3):350-360.

53. Ingelman-Sundberg M. Genetic polymorphisms of cytochrome $\mathrm{P} 450$ 2D6 (CYP2D6): clinical consequences, evolutionary aspects and functional diversity. Pharmacogenomics J. 2005;5(1):6-13.

54. Ingelman-Sundberg M, Sim SC. Pharmacogenetic biomarkers as tools for improved drug therapy; emphasis on the cytochrome P450 system. Biochem Biophys Res Commun. 2010;396(1):90-94.

55. Zhou SF. Polymorphism of human cytochrome P450 2D6 and its clinical significance: part II. Clin Pharmacokinet. 2009;48(12):761-804.

56. Hicks JK, Swen JJ, Thorn CF, et al. Clinical Pharmacogenetics Implementation Consortium guideline for CYP2D6 and CYP2C19 genotypes and dosing of tricyclic antidepressants. Clin Pharmacol Therapeut. 2013;93(5):402-408.

57. Jovanovic N, Bozina N, Lovric M, Medved V, Jakovljevic M, Peles $\mathrm{AM}$. The role of CYP2D6 and $\mathrm{ABCB} 1$ pharmacogenetics in drug-naive patients with first-episode schizophrenia treated with risperidone. Eur J Clin Pharmacol. 2010;66(11):1109-1117.

58. Xiang Q, Zhao X, Zhou Y, Duan JL, Cui YM. Effect of CYP2D6, CYP3A5, and MDR1 genetic polymorphisms on the pharmacokinetics of risperidone and its active moiety. J Clin Pharmacol. 2010;50(6):659-666.
59. Bozina N, Jovanovic N, Lovric M, Medved V. Clinical significance of a CYP2D6 poor metabolizer - a patient with schizophrenia on risperidone treatment. Ther Drug Monit. 2008;30(6):748-751.

60. Knegtering R, Baselmans P, Castelein S, Bosker F, Bruggeman R, van den Bosch RJ. Predominant role of the 9-hydroxy metabolite of risperidone in elevating blood prolactin levels. Am J Psychiatry. 2005;162(5): 1010-1012.

61. Melkersson KI. Prolactin elevation of the antipsychotic risperidone is predominantly related to its 9-hydroxy metabolite. Hum Psychopharmacol. 2006;21(8):529-532.

62. Troost PW, Lahuis BE, Hermans MH, et al. Prolactin release in children treated with risperidone: impact and role of CYP2D6 metabolism. $J$ Clin Psychopharmacol. 2007;27(1):52-57.

63. Ngamsamut N, Hongkaew Y, Vanwong N, et al. 9-Hydroxyrisperidoneinduced hyperprolactinaemia in Thai children and adolescents with autism spectrum disorder. Basic Clin Pharmacol Toxicol. 2016;119(3): 267-272.

64. Wang L, Yu L, Zhang AP, et al. Serum prolactin levels, plasma risperidone levels, polymorphism of cytochrome P450 2D6 and clinical response in patients with schizophrenia. J Psychopharmacol. 2007;21(8):837-842.

65. Nasrallah HA. Atypical antipsychotic-induced metabolic side effects: insights from receptor-binding profiles. Mol Psychiatry. 2008;13(1):27-35.

66. Nasrallah HA. Metabolic findings from the CATIE trial and their relation to tolerability. CNS Spectrums. 2006;11(7 Suppl 7):32-39.

67. Lane HY, Liu YC, Huang CL, et al. Risperidone-related weight gain: genetic and nongenetic predictors. J Clin Psychopharmacol. 2006;26(2):128-134.

68. Correia CT, Almeida JP, Santos PE, et al. Pharmacogenetics of risperidone therapy in autism: association analysis of eight candidate genes with drug efficacy and adverse drug reactions. Pharmacogenomics $J$. 2010;10(5):418-430.

69. Kakihara S, Yoshimura R, Shinkai K, et al. Prediction of response to risperidone treatment with respect to plasma concencentrations of risperidone, catecholamine metabolites, and polymorphism of cytochrome P450 2D6. Int Clin Psychopharmacol. 2005;20(2):71-78.

70. Almoguera B, Riveiro-Alvarez R, Lopez-Castroman J, et al. CYP2D6 poor metabolizer status might be associated with better response to risperidone treatment. Pharmacogenet Genomics. 2013;23(11):627-630.

71. Youngster I, Zachor DA, Gabis LV, et al. CYP2D6 genotyping in paediatric patients with autism treated with risperidone: a preliminary cohort study. Dev Med Child Neurol. 2014;56(10):990-994.

72. Fleeman N, Dundar Y, Dickson R, et al. Cytochrome P450 testing for prescribing antipsychotics in adults with schizophrenia: systematic review and meta-analyses. Pharmacogenomics J. 2011;11(1):1-14.

73. Ravyn D, Ravyn V, Lowney R, Nasrallah HA. CYP450 pharmacogenetic treatment strategies for antipsychotics: a review of the evidence. Schizophr Res. 2013;149(1-3):1-14.

74. de Leon J, Susce MT, Pan RM, Fairchild M, Koch WH, Wedlund PJ. The CYP2D6 poor metabolizer phenotype may be associated with risperidone adverse drug reactions and discontinuation. J Clin Psychiatry. 2005;66(1):15-27.

75. Nussbaum LA, Dumitrascu V, Tudor A, Gradinaru R, Andreescu N, Puiu M. Molecular study of weight gain related to atypical antipsychotics: clinical implications of the CYP2D6 genotype. Rom J Morphol Embryol. 2014;55(3):877-884.

76. Ellingrod VL, Miller D, Schultz SK, Wehring H, Arndt S. CYP2D6 polymorphisms and atypical antipsychotic weight gain. Psychiatr Genet. 2002;12(1):55-58.

77. Turrone P, Kapur S, Seeman MV, Flint AJ. Elevation of prolactin levels by atypical antipsychotics. Am J Psychiatry. 2002;159(1):133-135.

78. Stevens JR, Kymissis PI, Baker AJ. Elevated prolactin levels in male youths treated with risperidone and quetiapine. J Child Adolesc Psychopharmacol. 2005;15(6):893-900.

79. Calarge CA, Ellingrod VL, Acion L, et al. Variants of the dopamine D2 receptor gene and risperidone-induced hyperprolactinemia in children and adolescents. Pharmacogenet Genomics. 2009;19(5):373-382. 
80. Roke Y, van Harten PN, Franke B, Galesloot TE, Boot AM, Buitelaar JK. The effect of the Taq1A variant in the dopamine $\mathrm{D}(2)$ receptor gene and common CYP2D6 alleles on prolactin levels in risperidone-treated boys. Pharmacogenet Genomics. 2013;23(9):487-493.

81. Hongkaew Y, Ngamsamut N, Puangpetch A, et al. Hyperprolactinemia in Thai children and adolescents with autism spectrum disorder treated with risperidone. Neuropsychiatr Dis Treat. 2015;11:191-196.

82. dos Santos Junior A, Henriques TB, de Mello MP, et al. Hyperprolactinemia in children and adolescents with use of risperidone: clinical and molecular genetics aspects. J Child Adolesc Psychopharmacol. 2015;25(10):738-748.

83. Ozdemir V, Bertilsson L, Miura J, et al. CYP2D6 genotype in relation to perphenazine concentration and pituitary pharmacodynamic tissue sensitivity in Asians: CYP2D6-serotonin-dopamine crosstalk revisited. Pharmacogenet Genomics. 2007;17(5):339-347.

84. Sukasem C, Hongkaew Y, Ngamsamut N, et al. Impact of pharmacogenetic markers of CYP2D6 and DRD2 on prolactin response in risperidone-treated Thai children and adolescents with autism spectrum disorders. J Clin Psychopharmacol. 2016;36(2):141-146.

85. Bernard S, Neville KA, Nguyen AT, Flockhart DA. Interethnic differences in genetic polymorphisms of CYP2D6 in the U.S. population: clinical implications. Oncologist. 2006;11(2):126-135.

86. Pringsheim T, Panagiotopoulos C, Davidson J, Ho J; The Canadian Alliance for Monitoring Effectiveness and Safety of Antipsychotics in Children (CAMESA) Guideline Group. Evidence-based recommendations for monitoring safety of second-generation antipsychotics in children and youth. Paediatr Child Health. 2011;16(9):581-589.

87. Haddad PM, Wieck A. Antipsychotic-induced hyperprolactinaemia: mechanisms, clinical features and management. Drugs. 2004;64(20):2291-2314

88. Cabaleiro T, Ochoa D, Lopez-Rodriguez R, et al. Effect of polymorphisms on the pharmacokinetics, pharmacodynamics, and safety of risperidone in healthy volunteers. Hum Psychopharmacol. 2014;29(5): 459-469.

89. Dodgen TM, Eloff A, Mataboge C, Roos LJ, van Staden WC, Pepper MS. Risperidone-associated adverse drug reactions and CYP2D6 polymorphisms in a South African cohort. Appl Transl Genom. 2015;5: 40-46.

90. Vandenberghe F, Guidi M, Choong E, et al. Genetics-based population pharmacokinetics and pharmacodynamics of risperidone in a psychiatric cohort. Clin Pharmacokinet. 2015;54(12):1259-1272.

91. de Leon J, Susce MT, Pan RM, Koch WH, Wedlund PJ. Polymorphic variations in GSTM1, GSTT1, PgP, CYP2D6, CYP3A5, and dopamine D2 and D3 receptors and their association with tardive dyskinesia in severe mental illness. J Clin Psychopharmacol. 2005;25(5): $448-456$.

92. Gaedigk A. Complexities of CYP2D6 gene analysis and interpretation. Int Rev Psychiatry. 2013;25(5):534-553
93. Stingl JC, Brockmoller J, Viviani R. Genetic variability of drug-metabolizing enzymes: the dual impact on psychiatric therapy and regulation of brain function. Mol Psychiatry. 2013;18(3):273-287.

94. Hendset M, Molden E, Knape M, Hermann M. Serum concentrations of risperidone and aripiprazole in subgroups encoding CYP2D6 intermediate metabolizer phenotype. Ther Drug Monit. 2014;36(1):80-85.

95. Rau T, Wohlleben G, Wuttke H, et al. CYP2D6 genotype: impact on adverse effects and nonresponse during treatment with antidepressants - a pilot study. Clin Pharmacol Ther. 2004;75(5):386-393.

96. Alfaro CL, Lam YW, Simpson J, Ereshefsky L. CYP2D6 inhibition by fluoxetine, paroxetine, sertraline, and venlafaxine in a crossover study: intraindividual variability and plasma concentration correlations. J Clin Pharmacol. 2000;40(1):58-66.

97. Brynne N, Svanstrom C, Aberg-Wistedt A, Hallen B, Bertilsson L. Fluoxetine inhibits the metabolism of tolterodine-pharmacokinetic implications and proposed clinical relevance. Br J Clin Pharmacol. 1999;48(4):553-563.

98. Mannheimer B, von Bahr C, Pettersson H, Eliasson E. Impact of multiple inhibitors or substrates of cytochrome P450 2D6 on plasma risperidone levels in patients on polypharmacy. Ther Drug Monit. 2008;30(5):565-569.

99. Lisbeth P, Vincent H, Kristof M, Bernard S, Manuel M, Hugo N. Genotype and co-medication dependent CYP2D6 metabolic activity: effects on serum concentrations of aripiprazole, haloperidol, risperidone, paliperidone and zuclopenthixol. Eur J Clin Pharmacol. 2016;72(2):175-184.

100. Kim KA, Park PW, Liu KH, et al. Effect of rifampin, an inducer of CYP3A and P-glycoprotein, on the pharmacokinetics of risperidone. J Clin Pharmacol. 2008;48(1):66-72.

101. Besag FM, Berry D. Interactions between antiepileptic and antipsychotic drugs. Drug Safety. 2006;29(2):95-118.

102. Llerena A, Berecz R, Dorado P, de la Rubia A. QTc interval, CYP2D6 and CYP2C9 genotypes and risperidone plasma concentrations. J Psychopharmacol. 2004;18(2):189-193.

103. Steimer W, Zopf K, von Amelunxen S, et al. Allele-specific change of concentration and functional gene dose for the prediction of steady-state serum concentrations of amitriptyline and nortriptyline in CYP2C19 and CYP2D6 extensive and intermediate metabolizers. Clin Chem. 2004;50(9):1623-1633.

104. Loovers HM, van der Weide J. Implementation of CYP2D6 genotyping in psychiatry. Expert Opin Drug Metabol Toxicol. 2009;5(9):1065-1077.

105. Kirchheiner J, Brosen K, Dahl ML, et al. CYP2D6 and CYP2C19 genotype-based dose recommendations for antidepressants: a first step towards subpopulation-specific dosages. Acta Psychiatr Scand. 2001;104(3):173-192.

106. Borges S, Desta Z, Jin Y, et al. Composite functional genetic and comedication CYP2D6 activity score in predicting tamoxifen drug exposure among breast cancer patients. J Clin Pharmacol. 2010;50(4):450-458.
Pharmacogenomics and Personalized Medicine

\section{Publish your work in this journal}

Pharmacogenomics and Personalized Medicine is an international, peerreviewed, open access journal characterizing the influence of genotype on pharmacology leading to the development of personalized treatment programs and individualized drug selection for improved safety, efficacy and sustainability. This journal is indexed on the American Chemical
Society's Chemical Abstracts Service (CAS). The manuscript management system is completely online and includes a very quick and fair peer-review system, which is all easy to use. Visit http://www.dovepress. com/testimonials.php to read real quotes from published authors. 